\title{
Le cimetière de l'église Saint-Symphorien au « Petit Hameau ", Sens (Yonne)
}

\section{Fabrice Henrion}

\section{(2) OpenEdition}

1 Journals

\section{Édition électronique}

URL : https://journals.openedition.org/cem/11257

DOI : 10.4000/cem. 11257

ISSN : 1954-3093

Éditeur

Centre d'études médiévales Saint-Germain d'Auxerre

\section{Édition imprimée}

Date de publication : 15 août 2009

Pagination : $21-23$

ISSN : 1623-5770

\section{Référence électronique}

Fabrice Henrion, «Le cimetière de l'église Saint-Symphorien au "Petit Hameau », Sens (Yonne) »,

Bulletin du centre d'études médiévales d'Auxerre / BUCEMA [En ligne], 13 | 2009, mis en ligne le 21 septembre 2009, consulté le 22 septembre 2022. URL : http://journals.openedition.org/cem/11257 ; DOI : https://doi.org/10.4000/cem. 11257

Ce document a été généré automatiquement le 22 septembre 2022.

\section{(c) (i) (9)}

Creative Commons - Attribution - Pas d'Utilisation Commerciale - Partage dans les Mêmes Conditions 4.0 International - CC BY-NC-SA 4.0

https://creativecommons.org/licenses/by-nc-sa/4.0/ 


\title{
Le cimetière de l'église Saint- Symphorien au " Petit Hameau », Sens (Yonne)
}

\author{
Fabrice Henrion
}

1 En amont d'un programme de construction de logements sociaux, une fouille préventive ${ }^{1}$ a été menée sur une parcelle réputée à l'emplacement de l'ancienne église Saint-Symphorien, disparue après la Révolution de 1789. Les origines de cette église ne sont pas très claires, ni même d'ailleurs son histoire et son évolution au cours du Moyen Âge et de l'époque moderne. On aurait été tenté d'accueillir avec intérêt l'idée qu'il puisse s'agir d'une fondation mérovingienne avec, en particulier, l'inhumation d'un certain Médère ${ }^{2}$ - ce qui justifiait par ailleurs notre engagement dans cette opération préventive -, mais le réexamen des sources montre clairement qu'il s'agit d'une invention moderne. Toutefois, c'est à partir du milieu du XII ${ }^{\mathrm{e}}$ siècle qu'apparaissent dans les textes l'église et la paroisse Saint-Symphorien, qui est bien, au début du XIII ${ }^{e}$ siècle, dans la liste des treize paroisses de Sens. En 1305, le pape Honorius III confirme la donation de l'église, avec celle de Saint-Romain, à l'abbaye Saint-Rémy, puis les deux cures sont réunies en 1468. La paroisse semble bénéficier de peu de revenus comme le suggèrent plusieurs témoignages mentionnant la difficulté de trouver un prêtre pour la desservir. À la fin du XVII siècle, les habitants obtiennent la permission de démolir la nef qui menace ruine; on ne sait ni quand ni comment elle fut rétablie, comme on peut le supposer. Au cours de la Révolution, la paroisse disparaît et les possessions vendues au titre des biens nationaux. L'église n'apparaît pas sur le cadastre de 1805, mais sans doute restait-elle à l'état de ruines puisqu'en 1814, lors du siège de Sens, elle sert de refuge à des prisonniers ennemis évadés de l'Hôtel-Dieu proche. Une partie seulement du cimetière paroissial a pu être étudiée et le recalage de l'église par superposition des plans anciens sur le parcellaire actuel montre qu'elle se situait sous la parcelle voisine, au sud.

2 Le diagnostic préalable, mené en 2004, avait proposé que les inhumations puissent être de la fin du haut Moyen Âge - carolingiennes, du fait de l'absence de trace de contenant 
et de mobilier -, ce qui serait venu étayer l'idée de l'ancienneté de la fondation et de la nécropole associée. Mais il est maintenant clairement établi que nous sommes en présence d'une portion du cimetière utilisée au cours $d u$ bas Moyen Âge, manifestement entre le XIV ${ }^{\mathrm{e}}$ - céramique à bord droit, à pâte beige et décor de flammules - et le $\mathrm{XVI}^{\mathrm{e}}$ siècle. Bien que les sources attestent de l'occupation funéraire jusqu'à la suppression de la paroisse en 1793, cette partie semble avoir été préservée, peut-être parce que la mémoire des tombes était encore vivace. Il est possible également que l'occupation se restreigne aux abords de l'église après le XVI ${ }^{\mathrm{e}}$ siècle ; il semble d'ailleurs que la paroisse soit modeste et peu peuplée aux XVII ${ }^{\mathrm{e}}$ et XVIII ${ }^{\mathrm{e}}$ siècles. Ce n'est qu'après la Révolution que des fosses de plantations et dépotoirs viennent perturber l'horizon funéraire et signent l'oubli de cette partie du cimetière.

3 La population inhumée est typique des cimetières paroissiaux de la fin du Moyen Âge. La représentation des adultes est bien plus importante que celle des enfants et, s'il existe une légère prédominance féminine, cette donnée est à prendre avec précaution puisque beaucoup de squelettes n'ont pu être sexués; cela ne renvoie donc pas véritablement l'image de l'ensemble de la population. L'état sanitaire des individus est plutôt médiocre d'un point de vue bucco-dentaire, mais peu d'entre eux sont atteints de pathologies, qu'elles soient d'origine traumatiques ou dégénératives. En ce qui concerne les modes d'inhumation, ceux-ci sont relativement simples - pleine terre avec ou sans linceul, coffrage, cercueil - et sont caractéristiques de la fin du Moyen Âge. Aucune sectorisation n'a été observée par rapport aux critères de l'âge, du sexe, des pathologies et des pratiques funéraires. Il est sans doute plus probable que l'organisation ait été effectuée en fonction de regroupements (familiaux?), perceptibles dans certains secteurs de la fouille.

4 En 2004, une inhumation orientée nord-sud avait été mise au jour et cette découverte avait incité le responsable du diagnostic à envisager plusieurs horizons dénonçant plusieurs phases d'occupation. La réalité est plus nuancée et l'on doit admettre une continuité d'utilisation de cette partie du cimetière dans la période donnée, avec maintien des lieux et superposition des inhumations. Quant à cette orientation particulière par rapport à l'ensemble, elle reste un unicum sur lequel le diagnostic était justement tombé.

Enfin, l'autre apport de cette étude est d'alimenter, certes modestement, la connaissance de Sens antique en pointant, là où la carte archéologique montrait un vide, un habitat très arasé et perturbé. Les quelques tesselles de mosaïque recueillies dans les comblements de sépultures renforcent également la nature de l'occupation environnante. 


\section{NOTES}

1. Placée sous ma responsabilité, l'équipe était constituée de Xavier D'aire (dessin), Kateline Ducat (fouille), Gilles Fèvre (dessin) et Raphaëlle Lefèbvre (anthropologie). Nous avons, en outre, bénéficié de l'aide précieuse de bénévoles: André et Michèle Auclair, Roselyne Beyaert, Daniel Genser, Michel Lehup, Christophe Leleu, Elise Leleu, Agathe Sapin, Jean-Claude et Monique Tamalet. Qu'ils soient tous très vivement remerciés.

2. Assimilé à Richer, évêque de Sens vers 627, cf. abbé H. BOUVIER, Histoire de l'église et de l'ancien archidiocèse de Sens, t. 1 (Des origines à l'an 1122), Amiens, 1906, en particulier p. 118-121. Encore au $\mathrm{XVIII}^{\mathrm{e}}$ siècle, on signale dans l'église la présence du tombeau de Mederius, cf. SENS, Bibliothèque municipale, ms. 76 : Mémoire pour servir à l'histoire des archevêques de Sens par FENEL (1715), p. 171 et ms. 71 : Histoire de la ville de Sens, par le père Louis Anastase Guichard, religieux pénitent du troisième ordre de saint François du couvent de Picpus, 1727, $4^{\mathrm{e}}$ partie, chapitre 15, «La paroisse SaintSymphorien », p. 131-133.

INDEX

Index géographique : France/Sens

Mots-clés : cimetière, église 